Original Article

\title{
MICROBIAL SYNTHESIS OF SILVER NANOPARTICLES USING STREPTOMYCES SP. PG12 AND THEIR CHARACTERIZATION, ANTIMICROBIAL ACTIVITY AND CYTOTOXICITY ASSESSMENT AGAINST HUMAN LUNG (A549) AND BREAST (MCF-7) CANCER CELL LINES
}

\author{
PALLAVI S. S. ${ }^{a}$, MEGHASHYAMA PRABHAKARA BHATa, SREENIVASA NAYAKA ${ }^{{ }^{*}}$ \\ aP. G. Department of Studies in Botany, Karnatak University, Dharwad 580003, Karnataka, India
}

Email: sreenivasankud@gmail.com

Received: 23 Apr 2021, Revised and Accepted: 22 Jun 2021

\begin{abstract}
Objective: Synthesis of silver nanoparticles using Streptomyces sp. PG12 and their characterization, antimicrobial activity and cytotoxicity against A549 and MCF-7 cancer cell lines.

Methods: The silver nanoparticles were subjected to UV-Vis. spectroscopy, Fourier transform infrared spectroscopy (FTIR), scanning electron microscopy with energy-dispersive X-ray spectroscopy (SEM/EDS), high-resolution transmission electron microscopy (HR-TEM), zeta potential, and X-ray diffractometry (XRD) analyses. Further, the antimicrobial potential was determined by using the agar well diffusion method and cytotoxicity was determined with the help of cell viability (MTT) assay and reactive oxygen species (ROS) assay.

Results: The initial indication of silver nanoparticles synthesis was noticed by the colour change in the reaction mixture and the absorption maximum at $421 \mathrm{~nm}$ in UV-Vis. analysis; whereas, the FTIR analysis displayed the biological functional groups responsible for the capping and stabilization of silver nanoparticles. SEM and TEM micrographs revealed the surface morphology, spherical shape, and smallest particle size as $18.91 \mathrm{~nm}$. The EDS and XRD patterns confirmed the involvement of various elements during the synthesis of silver nanoparticles and the crystalline, face-centered cubic nature, respectively. The silver nanoparticles displayed considerable antimicrobial activity against human pathogens even at low MIC and MBC concentrations and exhibited increased anticancer activity against A549 and MCF-7 cell lines, where the ability of silver nanoparticles to significantly restrict the growth of tumour cells was observed at $\mathrm{IC}_{50}$ values of $69.04 \mu \mathrm{g} / \mathrm{ml}$ and $138.30 \mu \mathrm{g} / \mathrm{ml}$, respectively.
\end{abstract}

Conclusion: Streptomyces sp. PG12 synthesized silver nanoparticles show significant anticancer activity against A549 and MCF-7 cell lines.

Keywords: Silver nanoparticles, Streptomyces sp., Antimicrobial activity, ROS expression, Human lung and breast cancer cell lines

(C) 2021 The Authors. Published by Innovare Academic Sciences Pvt Ltd. This is an open access article under the CC BY license (https://creativecommons.org/licenses/by/4.0/)

DOI: https://dx.doi.org/10.22159/ijpps.2021v13i8.41876. Journal homepage: https://innovareacademics.in/journals/index.php/ijpps.

\section{INTRODUCTION}

Nanotechnology is the concept that deals with the production, manipulation, characterization, and applications of nano-scale materials whose size usually ranges between 1 to $100 \mathrm{~nm}$. Nanomaterials prepared from metals offer unique properties of size, shape, and larger surface area to volume ratio [1]. In the recent decade, these metal nanoparticles prepared using gold, silver, platinum, copper, zinc, lead, iron, and many more are extensively used for various applications in divergent fields such as nanomedicine, electrical, agriculture, pharmaceuticals, cosmetics, food industry, textiles, and data storage $[2,3]$.

Silver is more often considered for synthesizing nanoparticles due to potential antimicrobial, antioxidant, anti-inflammatory, and anticancer activities. The recent advancements in nano-science have pointed out the significance of silver nanoparticles (AgNPs) in the areas of biomedical, DNA sequencing, biological sensors, plasmonics, catalysis, energy generation, and clean water technology [4,5]. Generally, AgNPs are produced by one of two paths, i.e., 'top-down' or 'bottom-up' strategies via physical or chemical or biological synthesis routes. The physical and chemical techniques require more energy, thermal ablation, and hazardous chemicals that are carcinogenic and induce genotoxicity. Hence, due to its low cost, non-toxicity, and eco-friendly nature, the biological synthesis method is essential $[6,7]$.

The greener approach of AgNPs synthesis is carried out by employing biological resources like algae, lichens, bacteria, yeast, fungi, actinobacteria, and plant extracts. Among the microorganisms, bacteria are considered the ideal source for metal nanoparticles synthesis, owing to their metal resistance mechanism, which helps them reduce ionic silver $\left(\mathrm{Ag}^{+}\right)$into elemental $\left(\mathrm{Ag}^{\circ}\right) \mathrm{NPs}[8,9]$. The microbial synthesis method of AgNPs allows for safer, cheaper, and more stable metallic AgNPs as the microbes produce various secondary metabolites, which actively participate in the reduction, capping, and stabilization [10].

The increasing multi-drug resistance in human pathogenic microorganisms is of great concern, and there is an urgent need for the development of broad-spectrum antimicrobials to treat severe infections. The AgNPs have gained importance as the alternative for antibacterial and antifungal agents and help reduce toxicity, avoid the side effects in patients, and prevent pathogens $[11,12]$. Cancer is ranked top on the list of deadly diseases as the second leading cause for the most deaths across the globe, and the numbers are expected to increase further [13]. From the past few decades, AgNPs are extensively used as cytotoxic agents against various human cancers. The microbial AgNPs synthesized using species of Pseudomonas [14], Enterococcus [15], and Streptomyces [16, 17] have successfully prevented the growth of tumour cells.

Actinomycetes belong to Gram-positive, aerobic and filamentous bacteria with high $\mathrm{G}+\mathrm{C}$ content. Many of the Actinomycetales members are known for their peculiar capacity to produce bioactive secondary metabolites having properties from antimicrobial to anticancer and many more [18-20]. Because of these essential biological properties of actinobacterial secondary metabolites, the culture filtrate of Streptomyces sp. PG12 was to investigate for the extracellular synthesis of AgNPs and their evaluation for antimicrobial and anticancer potential.

\section{MATERIALS AND METHODS}

Collection of pathogens

The pathogenic microorganisms such as Staphylococcus aureus (MTCC6908), Pseudomonas aeruginosa (MTCC424), Enterococcus 
faecalis (MTCC6845), Escherichia coli (MTCC40), Alternaria alternata (MTCC2060), Fusarium oxysporum (MTCC2087), Candida albicans (MTCC227), and Candida glabrata (MTCC3814) were procured from Institute of Microbial Technology, Chandigarh, India.

\section{Isolation of actinobacterial strains}

During the present study, the marine samples were collected from Maravanthe beach, Kundapura, Karnataka, India. The serially diluted samples were inoculated onto starch casein agar (SCA) media plates. The plates were subjected to incubation at $30{ }^{\circ} \mathrm{C}$ for $5 \mathrm{~d}$, and 45 Actinomycete strains were isolated. From these 45 isolates, a single Actinomycete was selected for the green AgNPs synthesis and designated as strain PG12.

\section{Genotypic characterization of the isolate}

The fresh culture of strain PG12 was employed to extract genomic DNA using the instructions of Hi-PurA DNA purification kit manufacturers. The 16S rRNA gene was sequenced (Sanger Sequencing 3500 Series, Genetic Analyzer) and deposited to the NCBI database via nucleotide BLAST web portal. Similar DNA sequences were selected to construct a phylogenetic tree using MegAlign Pro 17 (DNASTAR Lasergene) software as per the standard procedures [21].

\section{Preparation of cell-free extract}

The strain PG12 was inoculated into a $250 \mathrm{ml}$ Erlenmeyer flask with sterile starch casein broth. A rotary shaker at a speed of $200 \mathrm{rpm}$ was used to incubate the culture flasks for $5 \mathrm{~d}$ at room temperature. After incubation, the centrifugation at $10000 \mathrm{rpm}$ (REMI R-24) for $15 \mathrm{~min}$ was done to obtain the cell-free extract for AgNPs synthesis [21].

\section{Biosynthesis of AgNPs}

For the AgNPs synthesis, about $100 \mathrm{ml}$ aqueous solution of $0.1 \mathrm{mmol}$ $\mathrm{AgNO}_{3}$ was mixed with $100 \mathrm{ml}$ cell-free supernatant of PG12 strain. After adjusting the $\mathrm{pH}$ at 8.0, incubation for $5 \mathrm{~d}$ under dark conditions was followed, and the reduction of silver ions $\left(\mathrm{Ag}^{+}\right)$was examined by observing the change in colour of the reaction mixture [21].

\section{Characterizations of AgNPs}

The reduction of $\mathrm{Ag}^{+}$into $\mathrm{Ag}^{\circ}$ was recorded using a double beam UVVisible spectrophotometer (UV-9600A, METASH Instruments, Shanghai, China). The probable biochemical functional groups responsible for stabilizing and capping AgNPs were determined by FTIR spectrophotometer (Nicolet 6700, Thermo Fisher Scientific, Waltham, Massachusetts, USA) scanning from 4000 to $400 \mathrm{~cm}^{-1}$ in transmittance mode. The morphology, shape, size, and elemental composition of AgNPs were analyzed with SEM/EDS (Jeol, JSMIT500 LA, Japan) and HR-TEM (FEI, TECNAI G2, F30) instruments. Further, the electrostatic stability and zeta potential was calculated (HORIBA nanoparticle analyzer SZ-100, Kyoto, Japan) along with the crystalline nature of synthesized AgNPs by X-ray diffractometer (Rigaku SmartLab SE, Austin, Texas, US).

\section{Antimicrobial activity of AgNPs}

The antagonistic activity of Streptomyces sp. PG12 cell-free extract mediated AgNPs were determined against pathogenic fungi and bacteria using the agar well diffusion method on potato dextrose agar and nutrient agar, respectively. The different volumes of AgNPs $(25,50,75$, and $100 \mu \mathrm{l})$ from the stock suspension of $50 \mu \mathrm{g} / \mathrm{ml}$ concentrations were poured in appropriate wells $(6 \mathrm{~mm})$ along with positive (streptomycin and fluconazole) and negative (distilled water) controls. The plates were incubated at $35{ }^{\circ} \mathrm{C}$ for $24 \mathrm{~h}$ for bacterial pathogens and at $35^{\circ} \mathrm{C}$ for $72 \mathrm{~h}$ for fungal pathogens. The formation of inhibition zones were measured as diameter in $\mathrm{mm}$ with the help of the Hi-antibiotic zone scale-C [22].

Evaluation of minimum inhibitory concentration (MIC) and minimum bactericidal concentration (MBC) of AgNPs

The MIC of the synthesized AgNPs on bacterial pathogens was determined with broth dilution assay in a 96-well microtitre plate with resazurin as standard, whereas; the MBC test was carried out on Mueller-Hinton agar plates. About $24 \mathrm{~h}$ incubation at $37{ }^{\circ} \mathrm{C}$ was used for the test plates, and the concentration where no growth of bacteria was observed on plates was recorded as the MIC and MBC values [22].

\section{Anticancer activity assessment of AgNPs}

The cytotoxic activity of strain PG12 mediated AgNPs was investigated by employing the 96-well plate MTT cell proliferation assay. The cancer cells viz. A549 and MCF-7 cell lines were procured from NCCS, Pune, India, and sub-cultured and maintained on Dulbecco modified eagle medium (D-MEM) before incubation in a $5 \% \mathrm{CO}_{2}$ incubator at $37^{\circ} \mathrm{C}$. The cancer cells were plated in a 96-well plate (Nunc, Thermo Scientific, Cat. No. 265300) at a cell density of 20,000 cells/well for MTT assay, and ROS assay 10,000 cells /200 $\mu \mathrm{l}$ was used. For MTT assay, $3.48 \mu \mathrm{g} / \mathrm{ml}$ camptothecin (MCF-7), 2.58 $\mu \mathrm{g} / \mathrm{ml}$ cisplatin (A549) were taken as standard, and only media with cells were taken as control; whereas, appropriate concentrations of AgNPs suspensions in dimethyl sulfoxide (DMSO) $(12.5,25,50,100$ and $200 \mu \mathrm{g} / \mathrm{ml}$ ) were added into respective wells. Finally, tumour cell viability was examined recording the absorbance at $570 \mathrm{~nm}$ on ELISA reader by keeping $630 \mathrm{~nm}$ as reference wavelength [23].

The ROS assay was conducted by treating the cells with test compounds with $\mathrm{IC}_{50}$ concentrations except for cell control in $200 \mu \mathrm{l}$ of culture medium and incubated the cells for $24 \mathrm{~h}$. During ROS expression study, 2', 7'-dichlorodihydrofluorescein diacetate (H2DCFDA) was used for staining the cells, which oxidizes and converts into fluorescent 2', 7'dichlorofluorescein (DCF) by the generation of intracellular ROS. The cells were observed under a confocal microscope with 488 and $535 \mathrm{~nm}$ excitation and emission wavelengths for ROS study. All the images were recorded at a different time of intervals using an inverted phase-contrast microscope (Biolink) [23].

\section{Statistical analysis}

All the analysis performed was in triplicate and the data represented as mean \pm standard deviation. The statistical analysis was performed by using GraphPad Prism 4.0 software (San Diego, California, USA).

\section{RESULTS AND DISCUSSION}

\section{Genotypic characterization of the isolate}

The 16S rRNA gene sequence of 1011 base pairs obtained from the strain PG12 was submitted to the NCBI database (Accession No. MN235876) and initially characterized by nucleotide BLAST to get homologous sequences. A neighbor-joining phylogenetic tree was constructed using the homologous sequences of various other species in which the strain PG12 showed the highest similarity with Streptomyces sp. strain Al-Dhabi-87 (fig. 1). Similarly, a strain CGG11n of actinobacteria identified based on 16S rRNA gene sequencing and phylogenetic tree analysis was reported [24].

\section{Visual and UV-Vis analysis}

The initial indication of AgNPs synthesis was noticed by the change in colour of the reaction mixture; the supernatant was orange-brown before adding $1 \mathrm{mmol} \mathrm{AgNO}_{3}$ solution, the colour turned dark brown after adding $\mathrm{AgNO}_{3}$ and incubation in the dark (fig. 2A). The further confirmation on the synthesis of AgNPs was determined by sharp absorption maximum at $421 \mathrm{~nm}$ in UV-Vis. spectrophotometer (fig. 2B). Similar observations about the colour change in the reaction mixture after mixing with $\mathrm{AgNO}_{3}$ were reported and mentioned that the colour change is due to reducing silver ions in the $\mathrm{AgNO}_{3}$ solution. Due to surface plasmon resonance (SPR) excitation, a sharp peak was obtained, confirming the AgNPs formation from the supernatant of strain PG12 $[25,26]$.

\section{FTIR analysis}

The FTIR analysis was carried out in transmittance mode from 4000 to $400 \mathrm{~cm}^{-1}$ to recognize possible biochemical functional groups responsible for the AgNPs capping and stabilization. The FTIR spectrum of strain PG12 mediated AgNPs shown various characteristic peaks, which could be related to specific functional groups (fig. 3 ). The broad intensity peak at $3270 \mathrm{~cm}^{-1}$ corresponds to H-bonded free alcohols/phenols, whereas the small intensity peak at $2925 \mathrm{~cm}^{-1}$ is attributed to $\mathrm{C}-\mathrm{H}$ stretching alkanes. The sharp, medium intensity peaks at 1725 and $1634 \mathrm{~cm}^{-1}$ were correlated to $\mathrm{C}=0$ bonded 
aldehydes and amides, respectively. The small intensity peaks at 1377 and $1229 \mathrm{~cm}^{-1}$ corresponded to $\mathrm{N}=\mathrm{O}$ bonded nitro compound $\left(\mathrm{R}-\mathrm{NO}_{2}\right)$ and $\mathrm{S}=0$ bonded sulfates and sulfonamides. The strong intensity peak at $1026 \mathrm{~cm}^{-1}$ relates to $\mathrm{C}-\mathrm{N}$ bonded amines, and the weak peak at 446 $\mathrm{cm}^{-1}$ is attributed to $\mathrm{C}-\mathrm{X}$ bonded halides. The functional groups that helped in the synthesis of AgNPs were identified by observing a shift in absorption spectra. These results suggest the critical role of biological molecules in the AgNPs synthesis along with stabilization by having the ability to link to metal. The presence of active functional groups indicates effective reduction and capping of AgNPs [27, 28].

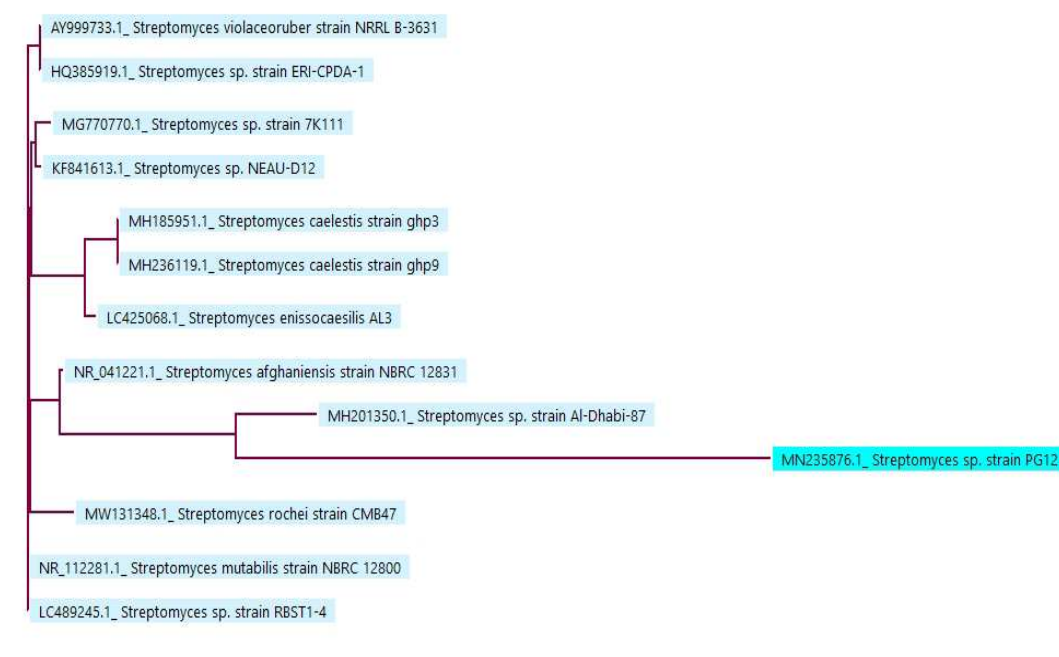

0.01

Fig. 1: Phylogenetic tree of the isolate Streptomyces sp. PG12

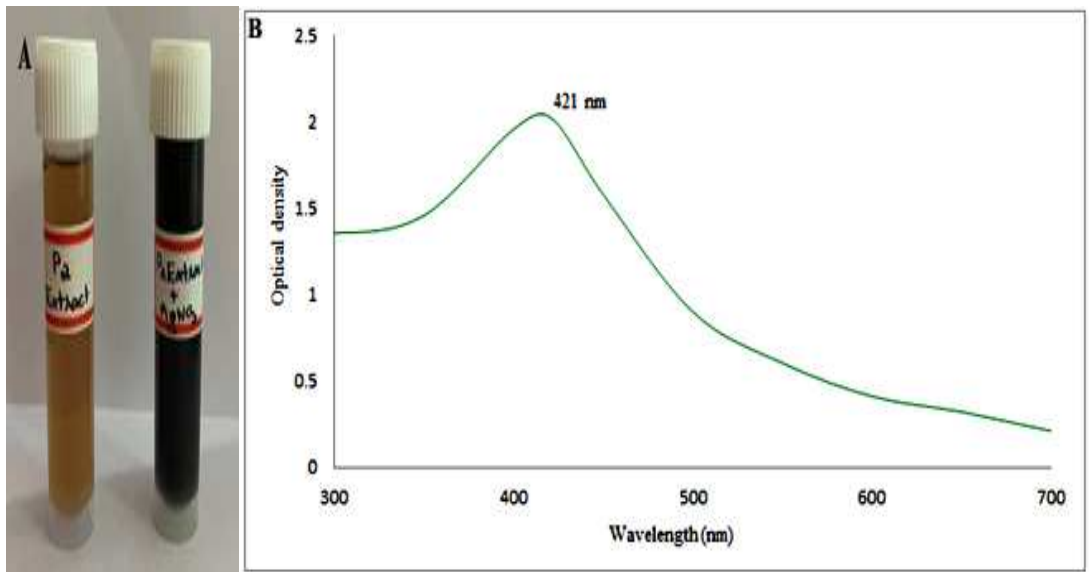

Fig. 2: Visual and UV-Vis. analysis of Streptomyces sp. PG12 AgNPs; A) colour change in the reaction mixture before and after adding $\mathrm{AgNO}_{3}, \mathrm{~B}$ ) A sharp peak obtained in UV-Vis. absorption spectrum

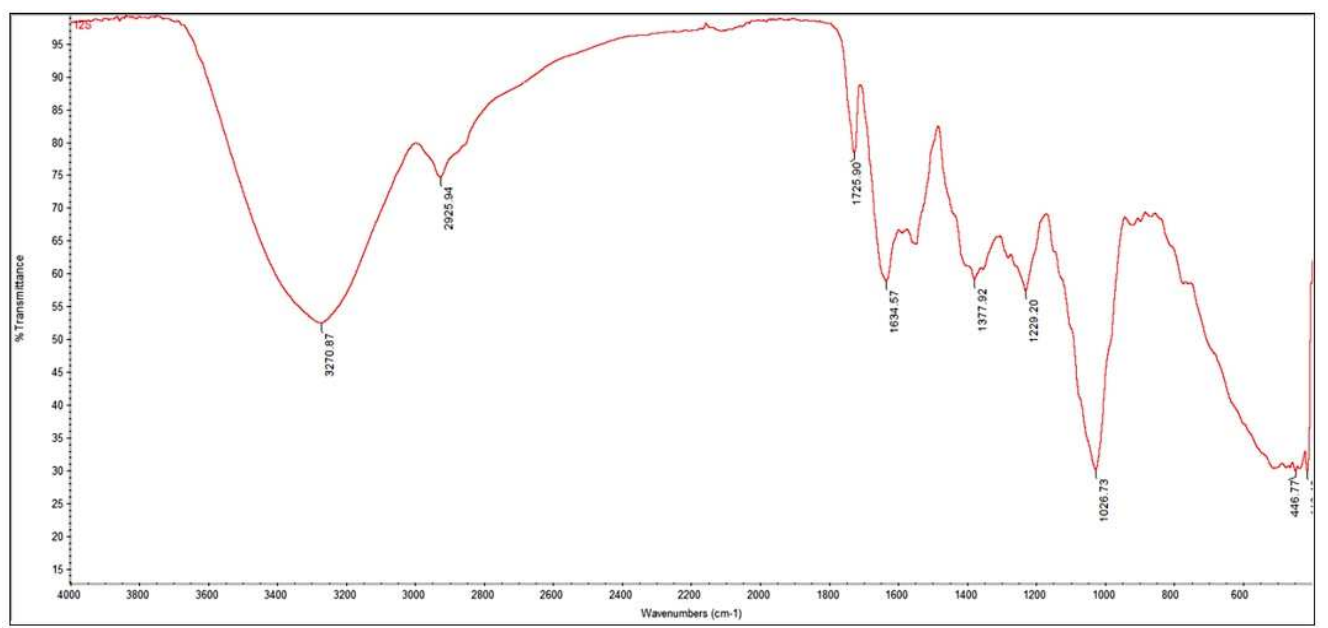

Fig. 3: FTIR spectrum of Streptomyces sp. PG12 AgNPs 


\section{SEM with EDS analysis}

The morphological details of synthesized AgNPs were ascertained by SEM imaging, where the shape and distribution of AgNPs were found to be spherical and polydispersed, respectively. The EDS analysis revealed $\mathrm{Ag}$ at $3 \mathrm{keV}$ and various elements such as $\mathrm{C}, \mathrm{O}, \mathrm{Na}, \mathrm{Cl}, \mathrm{K}$, and $\mathrm{Ca}$, which involved the capping of synthesized AgNPs (fig. 4A and
4B). The previous SEM analysis results of green AgNPs suggested the spherical shape, poly-dispersed AgNPs from the microbial origin, and most of the particles had a smooth surface with a compact arrangement. Similarly, the strong signal peak at $3 \mathrm{keV}$ in the EDS spectrum was due to the SPR of metallic silver. The analysis confirmed AgNPs synthesis with suggesting silver as the significant ingredient element $[29,30]$.
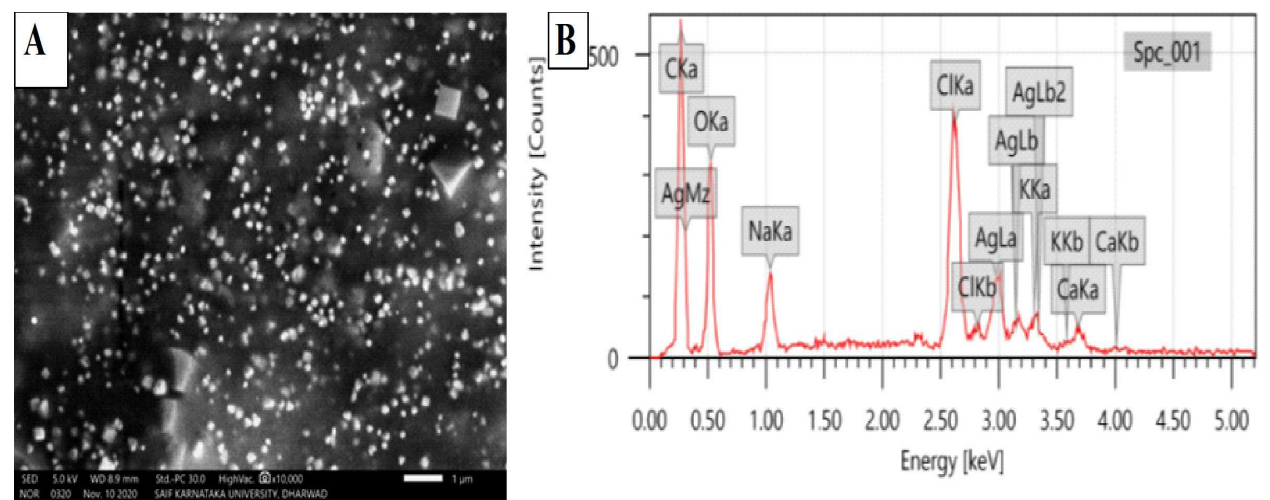

Fig. 4: SEM with EDS analysis of Streptomyces sp. PG12 AgNPs, A) SEM image showing morphology and distribution of AgNPs, B) EDS spectrum showing peaks for various elements

\section{HR-TEM analysis}

TEM analysis was performed to understand the morphological details of synthesized AgNPs, and the images confirmed the spherical shape of synthesized AgNPs (fig. 5A). The TEM data depicted the poly-dispersed nature of AgNPs with few agglomerates, and the AgNPs ranged from 20 to $32 \mathrm{~nm}$ in size with the smallest particle size of $18.91 \mathrm{~nm}$ (fig. 5B).
These findings agreed with the previous studies on TEM analysis of AgNPs, where the biogenic AgNPs were spherical, poly-dispersed, and ranged from 20 to $50 \mathrm{~nm}$ in size. The TEM micrograph also revealed the uneven distribution of AgNPs with a negligible amount of agglomeration; the small sizes of particles have a crucial role in the penetration process inside microbial cells to induce a cascade of events that lead to cell death $[31,32]$.

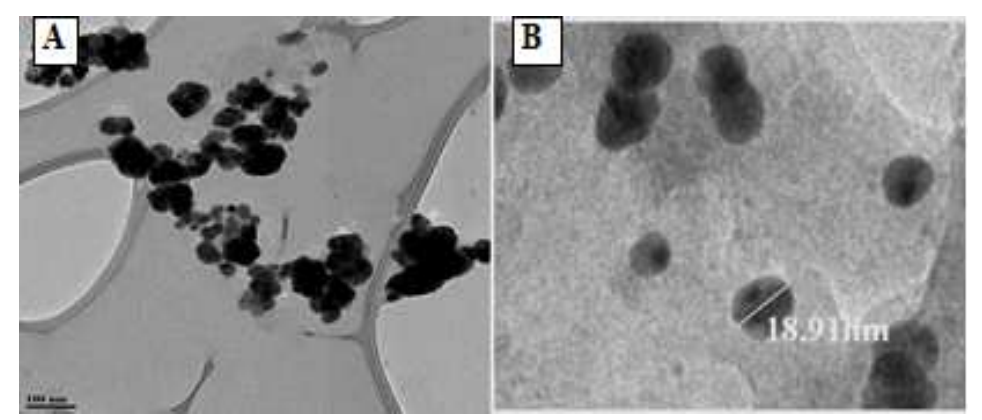

Fig. 5: HR-TEM analysis of Streptomyces sp. PG12 AgNPs, A) TEM micrograph showing surface morphology and distribution of AgNPs, B) Image showing average size of AgNPs

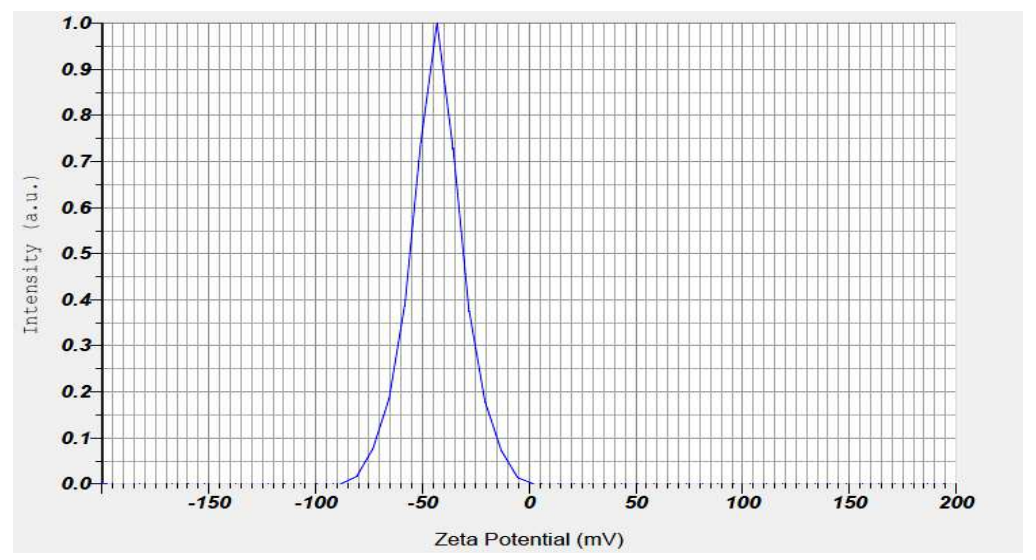

Fig. 6: Graph showing zeta potential of Streptomyces sp. PG12 AgNPs 


\section{Zeta potential analysis}

The stability of synthesized AgNPs was determined with zeta potential studies and the potential value of Streptomyces sp. PG12 AgNPs were determined to be $-43.2 \mathrm{mV}$ (fig. 6). Along with the stability, zeta analysis indicated the high dispersivity and welldefined colloidal nature of the AgNPs. This result was well supported by the previous studies on zeta potentials of AgNPs, hinting that the higher negative value attributes to the higher stability of AgNPs [33, 34].

\section{XRD analysis}

The XRD pattern obtained from PG12 AgNPs indicated four firm Bragg's peaks in the $2 \theta$ range of $30^{\circ}$ to $80^{\circ}$, confirming the synthesis of AgNPs. The four Bragg's peaks were obtained at (111), (200), (220), and (311) for $2 \theta$ angles of $38.13^{\circ}, 46.21^{\circ}, 64.48^{\circ}$, and $77.42^{\circ}$ determined the face-centered cubic nature of the synthesized AgNPs (fig. 7). Similar XRD patterns were observed in previous studies on AgNPs from Streptomyces albogriseolus [35] and Streptomyces sp. AS3 [36], suggesting the large crystalline domain sizes corresponding to pure silver metal. According to the previous reports, the extra peaks were due to the bio-organic phase present on the surface of AgNPs, and the more width of the peaks relates to the smaller particle size. The obtained results of characteristic peaks were verified with the JCPDS database.

\section{Antimicrobial activity of AgNPs}

The dried AgNPs powder was washed and re-suspended in distilled water before testing antimicrobial activity on pathogenic microorganisms. Among the selected bacterial pathogens, E. faecalis was the most sensitive with inhibition zones of $19,21,21$, and $23 \mathrm{~mm}$ for 25, 50, 75, and $100 \mu \mathrm{l}$ of AgNPs suspensions, respectively. For fungal pathogens, AgNPs showed the highest activity against $A$. alternata with $18,19,20$, and $21 \mathrm{~mm}$ inhibition zones for $25,50,75$, and $100 \mu \mathrm{l}$, respectively; whereas $S$. aureus, P. aeruginosa, and $F$. oxysporum were found to be less sensitive for AgNPs (fig. 8). The previous antimicrobial activity results suggested that Streptomyces olivaceus (MSU3) mediated AgNPs effectively suppressed the growth of S. pneumoniae, S. mutant, K. pneumoniae, and E. coli at $30 \mu \mathrm{l}$ [37]. Similarly, Streptomyces parvus (Al-Dhabi-91) showed increased antimicrobial activity even at low concentrations against pathogenic bacteria. Also, they suggested that the AgNPs may interact with microbial cell walls and lipopolysaccharides and disrupt them. Finally, the AgNPs leads to cell death when entering into the bacterial cell and binds to enzymes, proteins, and DNA by disrupting the cellular biochemical reactions and DNA replication mechanism [38].

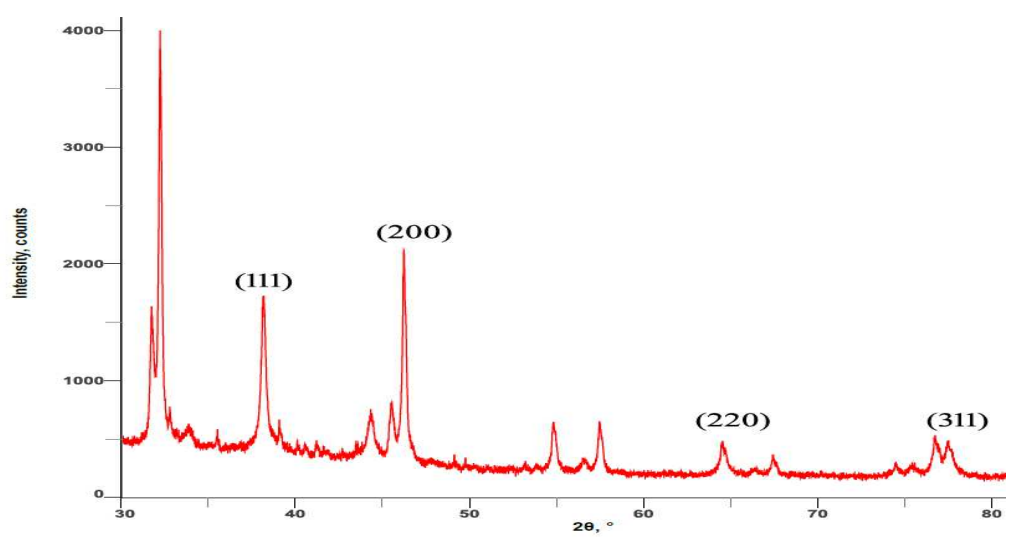

Fig. 7: XRD pattern of Streptomyces sp. PG12 AgNPs

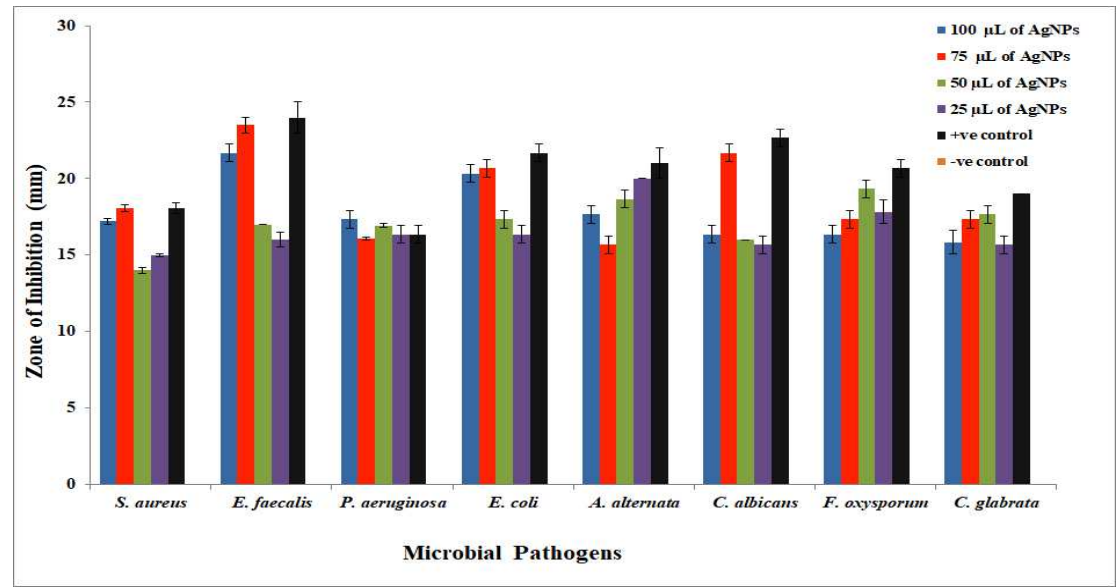

Fig. 8: Antimicrobial activity of Streptomyces sp. PG12 AgNPs against microbial pathogens, *values are the mean of three replicates \pm SD

\section{Evaluation of MIC and MBC}

The MIC can be defined as the minimum concentration of an antibiotic substance required to prevent bacterial growth, and the minimum concentration necessary to kill the pathogen is referred to as the MBC value. The biosynthesized AgNPs showed considerable MIC and MBC values against the test pathogens (table 1) and successfully inhibited the pathogens even at very low concentrations. Similar results were obtained in previous investigations, where the biological AgNPs at low concentrations showed high inhibitory activity against pathogens like E. coli, E. faecalis, S. aureus, and S. pneumoniae. They concluded that the AgNPs with smaller sizes provide a larger surface area for interaction with the microbial cell membrane, adding to the alterations in some primary functions of bacteria, such as permeability and cell respiration [39]. 
Table 1: MIC and MBC values of Streptomyces sp. PG12 AgNPs against pathogenic bacteria, *values are in mean three replicates \pm SD

\begin{tabular}{lll}
\hline S. No. & Name of the pathogen & MIC $(\boldsymbol{\mu g} / \mathbf{m l})$ \\
\hline 1. & S. aureus & 128 \\
2. & E. faecalis & 32 \\
3. & S. preumoniae & 32 \\
4. & E. coli & 64 \\
\hline
\end{tabular}

\section{Anticancer activity of AgNPs}

The cytotoxicity of AgNPs was evaluated on A549 and MCF-7 cell lines by employing both MTT assay and ROS expression study with 6.25 to $100 \mu \mathrm{g} / \mathrm{ml}$ AgNPs concentrations and IC 50 concentration at different time intervals, respectively. The AgNPs showed dose-dependent activity on A549 (fig. 9 A-G) and MCF7 (fig. 10 A-G) cell lines in the MTT assay; the increase in ROS generation with an increase in treatment time of AgNPs significantly inhibits the growth by causing damage to the tumour cells of A549 cell line (fig. 11 A-G) and MCF-7 cell line (fig. 12 A-G) was observed. The anticancer activity was evaluated by the conversion of MTT to purple-colored formazan by mitochondrial succinate dehydrogenase, and the cytotoxicity was determined by the concentration of AgNPs required to minimize the survival of tumour cells by $50 \%\left(\mathrm{IC}_{50}\right)$. The biosynthesized AgNPs exhibited considerable cytotoxic potential on A549 and MCF-7 cell lines with the IC $\mathrm{C}_{50}$ values of $69.04 \mu \mathrm{g} / \mathrm{ml}$ and $138.3 \mu \mathrm{g} / \mathrm{ml}$, respectively, and was evidenced by the shrinkage of cancer cells.

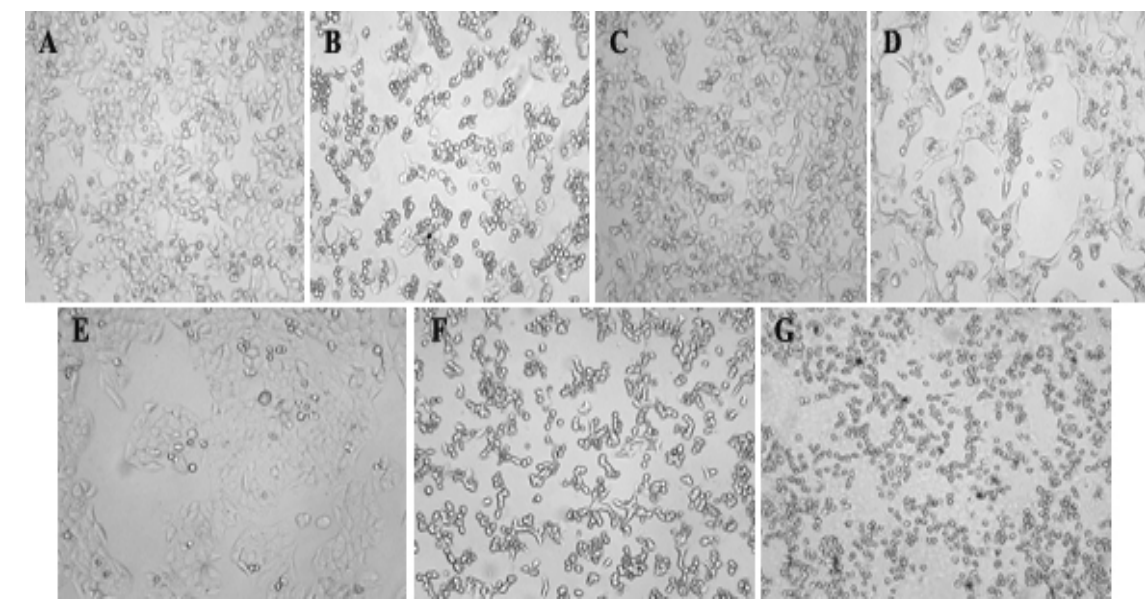

Fig. 9: MTT assay of Streptomyces sp. PG12 AgNPs on A549 cell line; A) control, B) standard, C) $6.25 \mu \mathrm{g} / \mathrm{ml}$ D) $12.5 \mu \mathrm{g} / \mathrm{ml}, \mathrm{E}) 25 \mu \mathrm{g} / \mathrm{ml}$, F) $50 \mu \mathrm{g} / \mathrm{ml}$, and G) $100 \mu \mathrm{g} / \mathrm{ml}$ of AgNPs
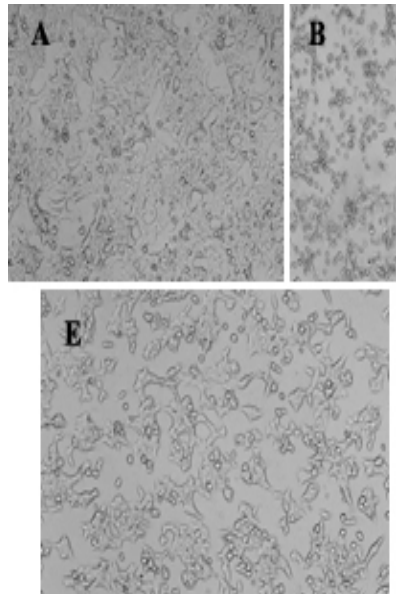
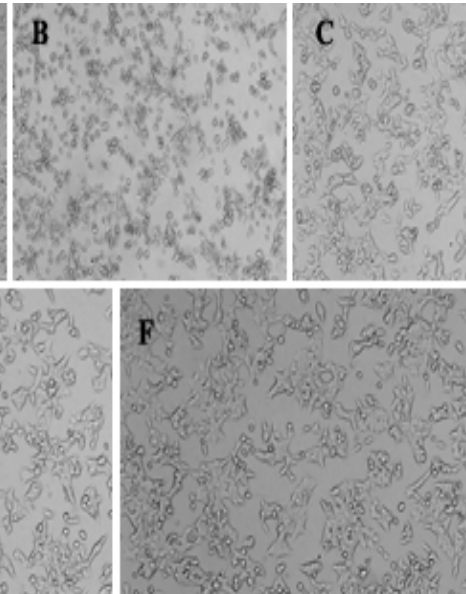
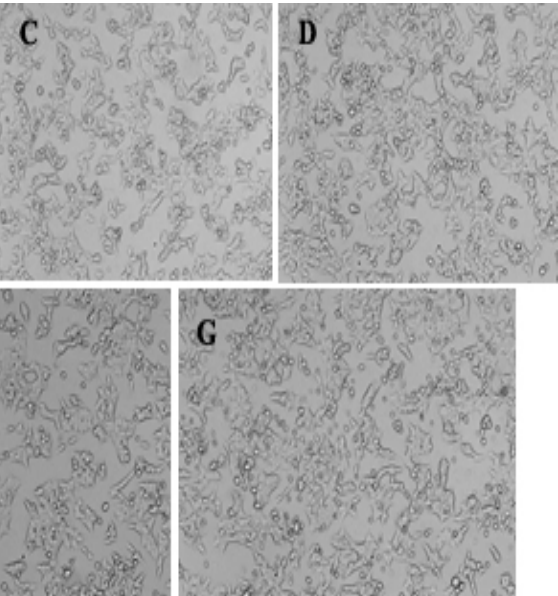

Fig. 10: MTT assay of Streptomyces sp. PG12 AgNPs on MCF7 cell line; A) control, B) standard, C) $6.25 \mu \mathrm{g} / \mathrm{ml}$ D) $12.5 \mu \mathrm{g} / \mathrm{ml}$, E) $25 \mu \mathrm{g} / \mathrm{ml}$, F) $50 \mu \mathrm{g} / \mathrm{ml}$, and G) $100 \mu \mathrm{g} / \mathrm{ml}$ of AgNPs

Similarly, previous studies conducted on the anticancer activities of AgNPs against MCF7 [40], CT26 [41], Caco-2 [42], and HePG2 [43] cell lines reported that the AgNPs showed dose-dependent activity on selected cell lines. The AgNPs treated cells were different from the untreated cells in cell shape, size, and other morphological details. In the ROS assay study, the treated cells were somewhat granular shaped with less well-defined colony morphology. The appearance of dissembled gaps between neighboring cells were characteristics of apoptosis, and the fluorescent green coloured cells represented necrotic cancer cells, which were dead due to the induced ROS. According to the previous reports, ROS are free radicals that play a vital role in the living system by causing cell damage and cell death. The rapidly increased ROS generation was due to the nature of surface, size, shape, and intensity of AgNPs. The overproduction of ROS induces apoptosis in several types of cancers, and cell death occurs due to an imbalance between pro and antioxidants levels inside the tumour cells $[23,44,45]$. 

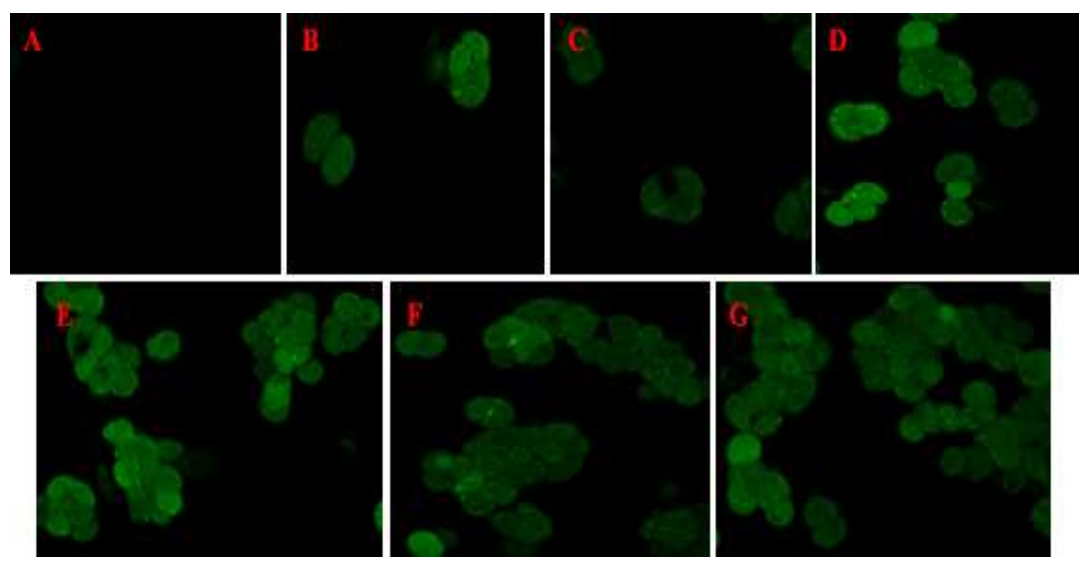

Fig. 11: ROS-mediated anticancer activity of Streptomyces sp. PG12 AgNPs on A549 cell line at different intervals of time; A) 0 min, B) 5 min, C) $15 \mathrm{~min}$, D) $30 \mathrm{~min}$, E) $60 \mathrm{~min}$, F) $90 \mathrm{~min}$, and G) $120 \mathrm{~min}$ of treatment time
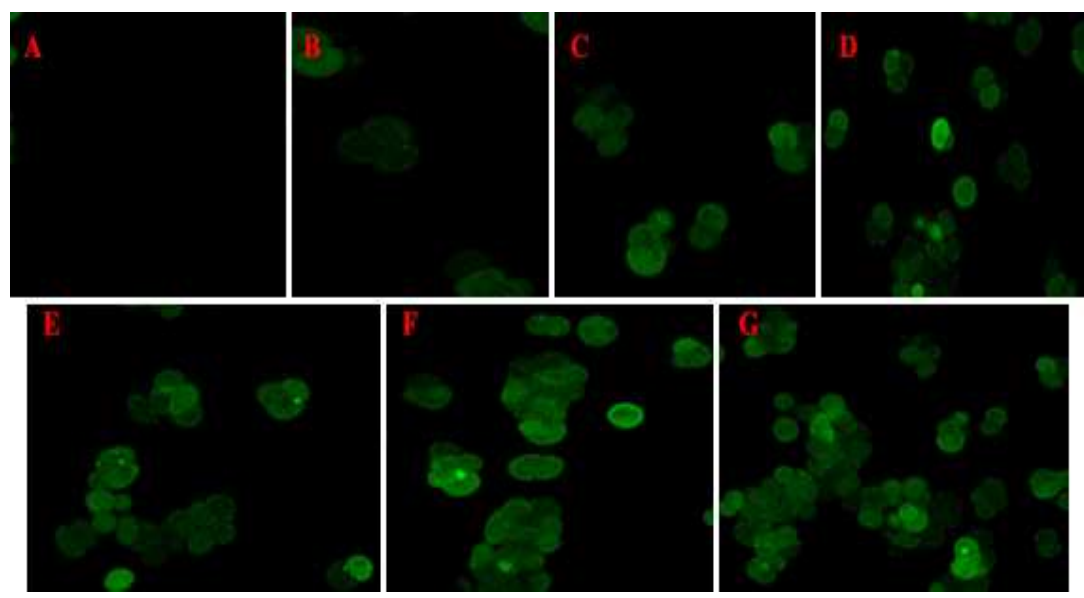

Fig. 12: RoS-mediated anticancer activity of Streptomyces sp. PG12 AgNPs on MCF7 cell line at different intervals of time; A) 0 min, B) 5 min, C) $15 \mathrm{~min}$, D) $30 \mathrm{~min}$, E) $60 \mathrm{~min}$, F) $90 \mathrm{~min}$, and G) $120 \mathrm{~min}$ of treatment time

\section{CONCLUSION}

The current study describes the synthesis of easy, non-toxic, and environmentally friendly extracellular AgNPs from Actinomycete isolate Streptomyces sp. PG12 culture supernatant. The primary indication regarding AgNPs synthesis was the colour change in the reaction mixture and confirmed by the UV-Vis. the absorption peak at $421 \mathrm{~nm}$. The biochemical functional groups involved in the capping, stabilization, and reduction of AgNPs were determined by FTIR analysis, and SEM and TEM microscopy ascertained the surface morphology. The spherical AgNPs were present in the range of 20 to $32 \mathrm{~nm}$ with the smallest particle size of $18.91 \mathrm{~nm}$. The biogenic AgNPs showed increased antimicrobial activity with lower MIC and MBC values. The biosynthesized AgNPs exhibited considerable anticancer activity, increasing ROS generation with increased exposure time on A549 and MCF-7 cell lines. The present results suggest that, Streptomyces sp. PG12 can be used for the mass synthesis of biological AgNPs, which could treat multidrug-resistant (MDR) microbial infections and as an anticancer agent after successful in vivo studies.

\section{ACKNOWLEDGMENT}

The authors would like to thank the Sophisticated Analytical Instrumentation Facility (SAIF), USIC, Karnatak University Dharwad, for extending instrumentation facilities.

\section{FUNDING}

\section{AUTHORS CONTRIBUTIONS}

SN designed the concept and supervised the experiments. PSS carried out the experimental analysis and wrote the manuscript. MPB wrote and edited the manuscript. All the authors read and approved the manuscript.

\section{CONFLICT OF INTERESTS}

The authors declare that there are no conflicts of interests.

\section{REFERENCES}

1. Srikar SK, Giri DD, Pal DB, Mishra PK, Upadhyay SN. Green synthesis of silver nanoparticles: a review. Green Sustainable Chem 2016;6:34-56.

2. Menon S, Rajeshkumar S, Venkat KS. A review on biogenic synthesis of gold nanoparticles, characterization, and its applications. Resour Effic Technol 2017;1-12.

3. Ahmad S, Munir S, Ullah A, Khan B, Ali J, Bilal M, et al. Green nanotechnology: a review on green synthesis of silver nanoparticles-an eco-friendly approach. Int J Nanomed 2019;14:5087-107.

4. Rafique M, Sadaf IM, Rafique S, Tahir MB. A review on green synthesis of silver nanoparticles and their applications. Artif Cells Nanomed Biotechnol 2017;45:1272-91.

5. Tarannum N, Divya, Gautam YK. Facile green synthesis and applications of silver nanoparticles: a state-of-the-art review. RSC Adv 2019;9:34926-48.

6. Duran N, Nakazato G, Seabra AB. Antimicrobial activity of biogenic silver nanoparticles, and silver chloride nanoparticles: 
an overview and comments. Appl Microbiol Biotechnol 2016;100:6555-70.

7. Gahlawat G, Choudhury AR. A review on the biosynthesis of metal and metal salt nanoparticles by microbes. RSC Adv 2019;9:12944-67.

8. de-Souza TAJ, Souza LRR, Franchi LP. Silver nanoparticles: an integrated view of green synthesis methods, transformation in the environment, and toxicity. Ecotoxicol Environ Saf 2019;171:691-700.

9. Garg D, Sarkar A, Chand P, Bansal P, Gola D, Sharma S, et al. Synthesis of silver nanoparticles utilizing various biological systems: mechanisms and applications-a review. Prog Biomater 2020;9:81-95.

10. Ali MA, Ahmed T, Wu W, Hossain A, Hafeez R, Masum MMI, et al. Advancements in plant and microbe-based synthesis of metallic nanoparticles and their antimicrobial activity against plant pathogens. Nanomater 2020;10:1146-70.

11. Shirley, Dayanand A, Sreedhar B, Dastager SG. Antimicrobial activity of silver nanoparticles synthesized from novel Streptomyces species. Dig J Nanomater Bios 2010;5:447-51.

12. Khair Allah DH, Al-Charrakh AH, Al-Dujaili NH. Antimicrobial activity of silver nanoparticles biosynthesized by Streptomyces spp. Ann Trop Public Health 2020;22:301-14.

13. Siegel RL, Miller KD, Jemal ADVM. Cancer statistics-2020. CA Cancer J Clin 2020;10:1-24.

14. Ramalingam V, Rajaram R, Premkumar C, Santhanam P, Dhinesh P, Vinothkumar $\mathrm{P}$, et al. Biosynthesis of silver nanoparticles from the deep-sea bacterium Pseudomonas aeruginosa JQ989348 for antimicrobial, antibiofilm, and cytotoxic activity. J Basic Microbiol 2013;53:1-9.

15. Rajeshkumar S, Malarkodi C, Vanaja M, Annadurai G. Anticancer and enhanced antimicrobial activity of biosynthesized silver nanoparticles against clinical pathogens. J Mol Struct 2016;1116:165-73.

16. Shanmugasundaram T, Radhakrishnan M, Gopikrishnan V, Pazhanimurugan R, Balagurunathan R. A study of the bactericidal, anti-biofouling, cytotoxic and antioxidant properties of actinobacterial synthesized silver nanoparticles. Colloids Surf B 2013;111:680-7.

17. Wypij M, Czarnecka J, Swiecimska M, Dahm H, Rai M, Golinska P. Synthesis, characterization and evaluation of antimicrobial and cytotoxic activities of biogenic silver nanoparticles synthesized from Streptomyces xinghaiensis OF1 strain. World J Microbiol Biotechnol 2018;34:23-36.

18. Abd-Elnaby H, Abo-Elala G, Abdel-Raouf U, Abd-elwahab A, Hamed M. Antibacterial and anticancer activity of marine Streptomyces parvus: optimization and application. Biotechnol Equip 2016;30:180-91.

19. Manimaran M, Kannabiran K. Actinomycetes-mediated biogenic synthesis of metal and metal oxide nanoparticles: progress and challenges. Lett Appl Microbiol 2017;64:401-8.

20. Kumari S, Tehri N, Gahlaut A, Hooda V. Actinomycetes mediated synthesis, characterization, and applications of metallic nanoparticles. Inorg Nano-Metal Chem 2020.

21. Sreenivasa N, Meghashyama BP, Pallavi SS, Bidhayak C, Dattatraya A, Muthuraj R, et al. Biogenic synthesis of silver nanoparticles using Paenibacillus sp. in vitro and their antibacterial, anticancer activity assessment against human colon tumour cell line. J Environ Biol 2021;42:118-27.

22. Nayaka S, Chakraborty B, Pallavi SS, Bhat MP, Shashiraj KN, Ghasti B. Synthesis of biogenic silver nanoparticles using Zanthoxylum rhetsa (Roxb.) DC seed coat extract as reducing agent and in vitro assessment of anticancer effect on A549 lung cancer cell line. Int J Pharm Res 2020;12:302-14.

23. Wypij M, Jedrzejewski T, Trzcinska Wencel J, Ostrowski M, Rai M, Golinska P. Green synthesized silver nanoparticles: antibacterial and anticancer activities, biocompatibility, and analyses of surface-attached proteins. Front Microbiol 2021;12:632505.

24. Railean Plugaru V, Pomastowski P, Wypij M, Szultka Mlynska M, Rafinska K, Golinska P, et al. Study of silver nanoparticles synthesized by an acidophilic strain of Actinobacteria isolated from the of Picea sitchensis forest soil. J Appl Microbiol 2016;120:1250-63.
25. Avilala J, Golla N. Antibacterial and antiviral properties of silver nanoparticles synthesized by marine actinomycetes. Int J Pharm Sci Res 2019;10:1223-8.

26. Hamed AA, Kabary H, Khedr M, Emam AN. Antibiofilm, the antimicrobial and cytotoxic activity of extracellular greensynthesized silver nanoparticles by two marine-derived actinomycete. RSC Adv 2020;10:10361-7.

27. Silva Vinhote NM, Caballero NED, Silva TA, Quelemes PV, deAraujo AR, de-Moraes ACM, et al. Extracellular biogenic synthesis of silver nanoparticles by actinomycetes from amazonic biome and its antimicrobial efficiency. African J Biotechnol 2017;16:2072-82.

28. Bizuye A, Gedamu L, Bii C, Gatebe E, Maina N. Molecularbased identification of actinomycetes species that synthesize antibacterial silver nanoparticles. Int J Microbiol 2020;1-17.

29. Bhat M, Chakraborty B, Kumar RS, Almansour AI, Arumugam N, Kotresha D, et al. Biogenic synthesis, characterization and antimicrobial activity of Ixora brachypoda (DC) leaf extract mediated silver nanoparticles. J King Saud Univ Sci 2021;33:101296.

30. Huq MA. Green synthesis of silver nanoparticles using Pseudoduganella eburnea MAHUQ-39 and their antimicrobial mechanisms investigation against drug-resistant human pathogens. Int J Mol Sci 2020;21:1510-23.

31. Fouda A, Hassan SE, Abdo AM, El-Gamal MS. Antimicrobial, antioxidant and larvicidal activities of spherical silver nanoparticles synthesized by endophytic Streptomyces spp. Biol Trace Elem Res 2020;195:707-24.

32. Sadhasivam S, Shanmugam P, Yun KS. Biosynthesis of silver nanoparticles by Streptomyces hygroscopicus and antimicrobial activity against medically important pathogenic microorganisms. Colloids Surf B 2010;81:358-62.

33. Dangi $\mathrm{P}, \mathrm{Op} \mathrm{J}$. Green synthesis, characterization, and in vitro antimicrobial efficacy of silver nanoparticles synthesized from Tectona grandis wood flour. Asian J Pharm Clin Res 2019;12:257-62.

34. Dayma PB, Mangrola AV, Suriyaraj SP, Dudhagara P, Patel RK. Synthesis of bio-silver nanoparticles using desert isolated Streptomyces intermedius and its antimicrobial activity. J Pharm Chem Biol Sci 2019;7:94-101.

35. Rodriguez Louis OE, Hernandez Delgadillo R, Sanchez Najera RI, Martinez Castanon GA, Nino Martinez N, Navarro MCS, et al. Green synthesis of silver nanoparticles and their bactericidal and antimycotic activities against oral microbes. J Nanomater 2016:1-10.

36. Samundeeswari A, Dhas SP, Nirmala J, John SP, Mukherjee A, Chandrasekaran N. Biosynthesis of silver nanoparticles using actinobacterium Streptomyces albogriseolus and its antibacterial activity. Biotechnol Appl Biochem 2012;59:503-7.

37. Devagi P, Suresh TC, Sandhiya RV, Sairandhry M, Bharathi S, Velmurugan $\mathrm{P}$, et al. Actinobacterial-mediated fabrication of silver nanoparticles and their broad-spectrum antibacterial activity against clinical pathogens. J Nanosci Nanotechnol 2020;20:2902-10.

38. Sanjivkumar M, Vaishnavi R, Neelakannan M, Kannan D, Silambarasan T, Immanuel G. Investigation on characterization and biomedical properties of silver nanoparticles synthesized by an actinobacterium Streptomyces olivaceus (MSU3). Biocatal Agric Biotechnol 2019;17:151-9.

39. Bharathi S, Kumaran S, Suresh G, Ramesh B, Sundari MSN. Phytosynthesis of silver nanoparticles using Hygrophila auriculata leaf extract and assessment of their antibacterial and antioxidant properties. Int J Appl Pharm 2018;10:119-25.

40. Al-Dhabi NA, Ghilan AKM, Esmail GA, Arasu MV, Duraipandiyan V, Ponmurugan K. Environmental friendly synthesis of silver nanomaterials from the promising Streptomyces parvus strain Al-Dhabi-91 recovered from the Saudi Arabian marine regions for antimicrobial and antioxidant properties. J Photochem Photobiol B 2019;197:111529-37.

41. Subbaiya R, Saravanan M, Priya AR, Shankar KR, Selvam M, Ovais $\mathrm{M}$, et al. Biomimetic synthesis of silver nanoparticles from Streptomyces atrovirens and their potential anticancer 
activity against human breast cancer cells. IET Nanobiotechnol 2017;11:965-72.

42. Bhaktiari Sardari A, Mashreghi M, Eshghi H, Behnam Rasouli F, Lashani E, Shahnavaz B. Comparative evaluation of silver nanoparticles biosynthesis by two cold-tolerant Streptomyces strains and their biological activities. Biotechnol Lett 2020;42:1985-99.

43. Salem SS, El-Belely EF, Niedbała G, Alnoman MM, Hassan SE, Eid AM, et al. Bactericidal and in vitro cytotoxic efficacy of silver nanoparticles (Ag-NPs) fabricated by endophytic actinomycetes and their use as a coating for the textile fabrics. Nanomater 2020;10:2082-102.

44. Zhu B, Li Y, Lin Z, Zhao M, Xu T, Wang C, et al. Silver nanoparticles induce HePG-2 cells apoptosis through ROSmediated signalling pathways. Nanoscale Res Lett 2016;11:198-205.

45. Antony A, Shrivastav N, Dubey S, Acharya A. Apoptosis inducing effect of silver nanoparticles synthesized using Magnolia champaca leaf extract on MCF-7 cell line. Int J Curr Pharm Res 2021;13:14-8. 